\title{
What's wrong with tombstoning and what does this tell us about responsibility for health?
}

\begin{abstract}
Using tombstoning (jumping from a height into water) as an example, this paper claims that public health policies and health promotion tend to assess the moral status of activities following a version of health maximising rule utilitarianism, but this does not represent common moral experience, not least because it fails to take into account the enjoyment that various health affecting habits brings and the contribution that this makes to a good life, variously defined. It is proposed that the moral status of health threatening activities should instead be defined by a version of act utilitarianism where both maximising value and method of calculation are decided by individuals. In this account personal responsibility for health is reduced to the obligation to undertake calculations effectively, comprising of two duties; epistemic and reflective. If there is an individual epistemic duty, it is plausible to suggest that health promotion should present information in a way which facilitates it, but despite the prevalent language of autonomous choice, discussion of health promotion messages for example related to drinking and smoking demonstrates that this currently does not happen. Health promotion strategies should seek to encourage reflection about the harm our health affecting behaviour causes others.
\end{abstract}

Key words Tombstoning

Responsibility for health

Health promotion

Utilitarianism

Public health

Author

Paul C Snelling

Principal Lecturer in adult nursing

Institute of Health and Society

University of Worcester

Henwick Grove,

Worcester,

WR2 6AJ.

E mail: $\quad$ p.snelling@worc.ac.uk

Phone: $\quad 01905542615$

This is a pre-copyedited, author-produced PDF of an article accepted for publication in Public Health Ethics following peer review. The version of record [Snelling, P. C. (2014). What's Wrong with Tombstoning and What Does This Tell Us About Responsibility for Health? Public Health Ethics, 7(2), 144-157] is available online at: http://phe.oxfordjournals.org/content/7/2/144 


\section{Introduction}

The practice of leaping from rocks or fixed man-made structures into the sea has been a recreational activity around coastlines for many years, but recent increasing frequency and fatalities ${ }^{1}$ have brought it to popular attention. Organisations like The Royal Society for the Prevention of Accidents (RoSPA) and Royal National Lifeboat Institution (RNLI) have issued warnings and information films about the dangers and offer advice about how to minimise risks (RNLI, undated a). There have been calls to ban the activity (Walker 2007); temporary dispersal orders have been granted at least in part to prevent tombstoning (BBC 2011a), and a youth was charged with Breaching the Peace following a tombstoning incident which necessitated lifeboat rescue (BBC 2007). Many videos of tombstoning can be found on video sharing websites, and it has been suggested that these should be removed or accompanied by warnings (Aiken 2009).

It is clear that many people undertake tombstoning in its various guises, while others disapprove of it, and in some cases this results in attempts to discourage, prevent or punish tombstoners. This paper considers the moral status of tombstoning, and by analogy, other forms of health threatening behaviour, beginning by analysing the reported responses to a tombstoning accident. Three versions of its moral status are identified, all utilitarian in origin, and yet resulting in sharply contrasting conclusions because the utility calculations use different variables. Calls to disapprove of or to prevent tombstoning are consistent with a notion of responsibility for health based on health-maximising rule utilitarianism which does not represent the moral reality of tombstoners. An alternative act-utilitarian approach is advanced using individually selected values and calculations. Responsibility for health, on this account, results in moral obligations in process rather than outcome, specifically two duties $^{2}$ : the epistemic duty and the reflective duty. These duties are outlined and their implication for public health discussed.

\section{The case of Sonny Wells}

Aged 20, Sonny Wells concluded a Sunday afternoon drinking with friends by ignoring signs stating 'No diving - maximum penalty $£ 500$ ' and jumping 30 feet off the pier at Southsea into just three feet of water. Pulled unconscious from the water and airlifted to hospital, his

\footnotetext{
${ }^{1}$ The Royal Society for the Prevention of Accidents (undated) state that in the five year period $2004-2008$ there were 139 incidents which required rescue, including 12 fatalities.

2 To paraphrase Goodin (1995), responsibilities are to utilitarianism what duties are to deontology. I have used the word duties because duties denote actions.
} 
neck was broken in three places, and though surgical intervention restored feeling and movement to his hands, he remains paralysed from the chest down, permanently confined to a wheelchair. A week after the accident, his parents released photographs of him in the Intensive Care Unit as a warning to others (BBC 2008a), and the following month he appeared from his bed in a video, used by Hampshire police to discourage people from tombstoning (BBC 2008b). Further videos featuring Sonny were made by the RNLI (undated) and the Dover District Community Safety Partnership (2011).

Sonny's mother is quoted as saying that:

[w]e know that we can't stop all youngsters and adults from tombstoning but if we can stop just a few of them from doing it then it would have been worthwhile. If they could see Sonny they wouldn't do it. It takes him half an hour to get dressed now instead of five minutes because he has to use his teeth.

(BBC 2011b).

The chairman of the Dover Community Safety Partnership, which funded the video is quoted in the same report: 'We all must play our part in discouraging this dangerous and potentially fatal activity.' These positions can be contrasted with that presented by RNLI and RoSPA. The websites of both organisations take the markedly different line that tombstoning is a high risk activity, and should be undertaken having taken steps to understand and minimise the risks. So, for RoSPA, the advice is:

Don't jump into the unknown. Consider the dangers before you take the plunge:

- Check for hazards in the water. Rocks or other objects may be submerged and difficult to see

- Check the depth of the water. Remember tides can rise and fall very quickly

- As a rule of thumb, a jump of ten metres requires a depth of at least five metres

- Never jump whilst under the influence of alcohol or drugs

- Check for access. It may be impossible to get out of the water

- Consider the risks to yourself and others. Conditions can change rapidly - young people could be watching and may attempt to mimic the activity. And, if you jump when you feel unsafe or pressured, you probably won’t enjoy the experience.

(RoSPA undated)

These statements are worthy of analysis because they express views about tombstoning from the viewpoint of those closest to it - from the parent, the tombstoner and the chairman of the local public body - rather than from professional bioethicists or politicians. The views about the moral status of tombstoning embedded within the statements are grounded in everyday experience, more closely allied to common-sense morality than moral or political philosophy. Archard (2011) argues that linkage of theory to common sense morality is inevitable, and that 
a defensible moral theory, which though 'at some distance from common-sense morality' (2011, p. 124) must at least be consistent with it. In arguing against the view that philosophers can be considered moral experts ${ }^{3}$, Archard claims that the role of philosophers should properly be that of advising or coaching non-philosophers, helping them to recognise the value of a better judgement. Brassington (2013) defends a role for philosophy and philosophical technique in bioethics, though recognises that it is charged that, 'in respect of private activity, the input of a moral philosopher is mere moralising' (p.22).

There is a significant difference between the outcome of a moral assessment and the process which arrived at it, as Archard points out, between the propositional and the performative. A philosophical analysis that refers to and builds upon reasoning by the actors concerned has the advantage of being readily understood and worthy of application; it is more coaching than moralising. However, grounding analysis in the common-sense morality of the protagonist is not a full inductive analysis, attempting to build a theory from the comments. Utilising a variant of reflective equilibrium neither builds nor applies theory; the aim is simply to show that established moral theory or at least more structured thinking is consistent with commonsense expressions.

\section{The Moral Appraisal of Tombstoning}

It can be argued that everything that we do is a matter for moral appraisal, at least because we could be doing something else (Seedhouse 2009). More realistically, the view that tombstoning is an act worthy of or even requiring moral appraisal is contained within Gert's (2005, p.9) 'correct' view of morality which, following Hobbes, is simply that morality is 'primarily concerned with the behaviour of people insofar as that behaviour affects others.' Bernard Williams (1985, p.12) makes a similar point. If this is accepted then tombstoning is a moral issue to the extent that it affects others and the relevant question becomes, to what extent does it affect others?

In the video produced by the Dover District Community Safety Partnership, Sonny said that

[i]t's not just what it does to you; it's what it does to your family...your friends, and it's just the way everyone has to live, you know...I have to have people on standby, on call, in case things go wrong. It's not just my life that's changed, their lives changed as well because it all revolves around me.

\footnotetext{
${ }^{3}$ But see Gordon (2012), for a response.
} 
Sonny's father Robbie Wells is quoted six weeks or so after the accident as saying; 'It's just selfish. It's the impact on people around you, not just the injuries; it's the years to come' (BBC 2008c). The advice from RoSPA and RNLI includes that the risks for others should be considered, identifying the possibility of setting a bad example to younger people as a special concern. These quotations support the view of tombstoning as a morally appraisable activity whose harms lie in its consequences especially insofar as they affect others.

\section{Three moral positions}

Illustrated by the comments above, it is possible to identify a number of different assessments of the moral status of tombstoning. The first would be that it is wrong and should be banned. Sonny passed a notice forbidding diving (BBC 2008b) on pain of being fined a considerable amount of money, and his mother talked of 'stopping' people from doing it. Signs advising, (or requiring - it's not always clear) patrons not to dive into swimming pools are common but this injunction does not apply to jumping in, feet first, an activity assumed to be safe enough into three feet of water from the edge of a swimming pool but not from a 30 foot pier. It is also not clear whether the prohibition covers diving from the location of the sign or whether it covers the whole pier, including the end furthest from the shore where, though there will be other dangers, shallow water (the circumstance that injured Sonny) is not one of them. A ban on diving is not a ban on tombstoning itself, only jumping in a specified manner (head first) from that particular part of that particular pier. Other forms of prevention, such as erecting a barrier or other means of making unsafe jumping more difficult, do not appear to have been reported. The intention to prevent people from injuring themselves has apparently been treated as justifying the passing of by-laws, but as the foregoing nitpickery demonstrates, formulating both a law and its justification presents considerable difficulties, not least in the question of whether the harm is considered serious enough to warrant criminalisation at all.

The second position is articulated by the Chairman of the Dover Community Safety Partnership who, significantly, claims that individuals should be discouraged rather than stopped from this undertaking 'this dangerous and potentially fatal activity.' Detailed inferences cannot be drawn on the basis of the limited information available, but the statement is consistent with at least two understandings of the word 'discourage'. The first is because of the potential harm caused, that tombstoning is a moral wrong, worthy of 
disapproval as well as discouragement, that is a position from tolerance ${ }^{4}$. The second is that discouragement is merely prudential; in this case the discouragement is similar to that which discourages high risk financial investments. Given that the wrongness of tombstoning lies in its effects on others, I am inclined to assign the former interpretation. The third position is stated outright by RoSPA and the RNLI, and amounts to saying that there is nothing wrong with tombstoning, as long as it is undertaken safely; and if the sensible advice offered is followed, the risk of possible adverse consequences can be minimised.

These three positions arrive at markedly different conclusions, though the moral methodologies share a significant feature, that is they agree that the wrongness of tombstoning rests in risk and occurrence of injury. It is not stated or implied anywhere that tombstoning is intrinsically wrong ${ }^{5}$. These positions are all consequentialist positions. But a characteristic of the presentation of the morality of tombstoning as a consequentialist morality is that it has resulted in three different conclusions; that it is wrong and should be prevented, that it is wrong but should not be prevented, and that it is permissible.

\section{Utilitarianism, public health, and private morality.}

It is widely recognised that the philosophical basis of public health is utilitarianism ${ }^{6}$ (Holland 2007, Rothstein 2004). But this is not to say that a single fully worked up utilitarian theory can be applied to all public health issues, calculations made, and (morally right) answers revealed, and though I assume that utilitarianism of one sort or another provides theoretical underpinning of public health generally, as well as the three positions on the moral status of tombstoning, it does not follow that tombstoning is a matter for public heath ethical analysis at all.

\footnotetext{
${ }^{4}$ This would be a paradigm example of tolerance generally understood as 'putting up with what you oppose' (McKinnon 2006 p.3). Toleration requires disapproval and a failure to stop something when you could, but a more modest version might include a failure to attempt to stop that of which you disapprove.

${ }^{5}$ It could be argued that there is something intrinsically wrong with tombstoning separate from its consequences, that it is simply in itself, a worthless thing to do, but this will not be considered further here.

${ }^{6}$ I do not wish to get bogged down in a dispute about whether the term 'consequentialism' should be used instead of the term' 'utilitarianism'. There is considerable overlap between the terms and standardly utilitarianism is the paradigm case of a consequentialist theory. Foot (1985) regards consequentialism as what is wrong with utilitarianism, and Jacobsen (2008) argues that there is such a thing as non-consequentialist utilitarianism. In is entry in the Stanford Encyclopeadia of Philosophy, Sinnett-Armstrong (2012) states that '.. there is no agreement on which theories count as consequentialist...' and though its broad meaning is known, shorn of specifying adjectives the naked term 'utilitarianism' is virtually useless as an action guide. I have used the term consequentialist to suggest that the wrongness of tombstoning rests in its consequences and thereafter I have used the term utilitarian as it is more likely to denote maximizing processes as I suspect that the term 'utilitarian' is more readily understood than the term 'consequentialist'. Certainly the term bioutilitarian appears in the bioethical literature but the term 'bioconsequentialist' generally does not.
} 
The quotations at the beginning of the paper concerned what ought to be done about tombstoning rather that saying that Sonny had acted immorally, but it should not be inferred from the absence of public condemnation that tombstoning is regarded by those advocating regulation as morally permissible or that it simply is not a matter for moral appraisal. It is more plausible to infer an unstated view that tombstoning is regarded as morally wrong by those who attempt to prevent it. As I have argued, and as much as any other activity, tombstoning is a moral matter to the extent that it affects others, and this assessment of private morality should be prior to any consideration that it is a legitimate matter for public health intervention. In place of inferences and suspected moralism in transferring public health ethics into the private realm (and vice versa), it is suggested that private immorality is a necessary but not sufficient condition of something being subject to public health interventions of the sort that coerces behaviour to some degree.

At least two problems present themselves with this sequencing. First there is the possibility of genuine disagreement about moral status that can apply at the level of general rules of action, specified application of the rules, and anywhere in between. A simple view that regulations preventing tombstoning are not legitimate because tombstoning is a private matter could be rejected as question begging (Coggon 2012). An attempt to make anything the subject of public health measures could be challenged with the response that the activity is morally permissible and therefore should not be regulated. There is not much unusual in this as political (and philosophical) disagreement forms the daily backdrop to public health dilemmas, but it is enough to suggest a revision of the view that private immorality forms a necessary condition for something to be a fitting subject for consideration of public health measures. This revision would need to be of the form that a plausible defence of the view that something is immoral is required, and this must be supported by enough people so that political legitimacy for public health measures can be claimed. This might be considered imprecise but at the minimum, a defence of a moral assessment is required and this in itself would be a considerable advance.

The second problem is one of consistency of moral method. Because private morality assesses the moral status of something and public morality assesses the morality, generally, of preventing that something or a response to that something, they are doing quite different things. The moral methodology of public health ethics does not transfer into the private domain and though this may frustrate those seeking a single overarching moral theory, it is an 
understandable position for many who regard moral theory as secondary to moral practice (Sterba 2005). Even if common morality is seen as being rooted in utilitarianism ${ }^{7}$, the variant which I claim is predominantly used in public health causes problems when transferred to the private realm. The reason why utilitarianism arrives at such contrasting conclusions in the moral assessments of tombstoning is that two of the variables used in the calculations are different.

\section{Acts and Rules.}

In the matter of health threatening behaviour, maximising calculations within public health ethics tend to operate at the level of rules rather than acts. There is reluctance for public health bodies to label (lawful) behaviours as immoral even as they attempt to reduce or prevent them. The reluctance to moralise or to override the greater (professed) good of respecting personal autonomy provides reasons why rules rather than acts are used because it allows the view to be both implied and inferred that it is tombstoning that is wrong rather than my acts of tombstoning or me as a tombstoner.

The problem for anyone considering going to the pier in order to jump off it is that the rules that tell him not that he ought not to do it are not his rules. The calculations have been formulated elsewhere by an unseen, unknown hand which has not taken his circumstances as much into account as they should have. The rule has been formulated, he might think, because people jump off the pier casually, after drinking, without checking the depth of water and the strength of the currents or who are improperly dressed or prepared. None of that applies to me - I'm dressed for it, I've researched the conditions and have come with support so that if an unforeseen event occurs I will be easily rescued. I'm not doing this on a whim; it's my main recreation, what keeps me going through the dreary week, the thought of gleefully flying through the air anticipating the invigorating shock of the cold briny sea. Who are you, he might ask, to tell me that I ought not to do it? His indignation will likely deepen when he realises that he's not being told, with justification, what he ought not to do, but rather what he must not do on pain of payment of a hefty fine. He's no anarchist - he really doesn't want to be in the position of considering breaking what he considers a unjust law, he just doesn't think it applies to him.

\footnotetext{
${ }^{7}$ See Hooker (2000a) on Sidgwick's Common-sense morality, and Greene (2013) for a review of the empirical evidence for dual level utilitarianism.
} 
His utilitarian calculation (and I assume that he does one), differs in at least three ways from that used by those arguing from a public health perspective. First, it concentrates on each act of jumping, recognising that the advice from RoSPA has been followed so that the risks have not only been minimised but also to some extent quantified. It's not an exact calculation, but the binary calculation of risk, that is the likelihood and the severity of the general consequences can both be considered, without necessarily considering the consequences of the consequences, ad absurdum, which has been offered as an objection to act-utilitarianism (Streumer 2003). Second, the calculation does what the rules cannot by allowing the individual to choose what to maximise, and then to perform the calculation using circumstances know only to him. When he has done these things he is able to give an answer not to the question of 'what is wrong with tombstoning?', but what, if anything, is wrong with me tombstoning from this place at this point in time, knowing these circumstances about my life. Third, the public health calculation concerns the outcomes of regulation, and not merely a moral appraisal of the regulated act or pastime.

\section{The maximisation of health.}

Public health utilitarianism, including as applied to health threatening behaviour, maximises health generally. This health maximisation could be either from a position that health is of intrinsic value (in utilitarian terms that it is the ultimate utility to be maximised); or it could be a matter of pragmatic calculation because using an instrumental account that health is valuable only insofar as it enables or restricts other activities contributing to the overall good, however defined and measured is just too difficult to calculate in a rule utilitarian approach. I assume that it is more likely to be the former, with health promotion tending to regard health in a narrow sense, largely physical, rather than within the World Health Organisation's famously all-encompassing definition. For example, a textbook aimed at nurses and healthcare professionals promotes not information facilitating autonomous choice, but has as a key message; 'Getting people to change their lifestyle requires them to make unpalatable changes...' (Upton and Thirlaway 2010, p.19 [my emphasis]), and regards behaviour choices evaluatively: 'People in the UK have always drunk alcohol, sometimes sensibly ${ }^{8}$ and sometimes stupidly...' (p.107).

\footnotetext{
${ }^{8}$ The word 'sensible' also appears in UK government documents, for example, Department of Health 2010, p. 10.
} 


\section{What does this tell us about responsibility for health?}

It will not have escaped many who have read this far that the discussion about the instance of tombstoning and the associated responsibilities and views about moral status are analogous to other forms of health threatening behaviours, which constitute a significant threat to health and are subject to a range of public health measures of various sorts, including health promotion. An advantage of using cases is that they can be simple and emotionally engaging. Inferential reasoning, implied rather than stated can take the form of ' $\mathrm{A}$ did $\mathrm{x}$ which is commonly judged as a bad action with bad consequences; therefore a general maxim forbidding $\mathrm{x}$ is a good maxim' (Adapted from Spranzi, 2012, p.483). A further inferential move from the good maxim (of forbidding ${ }^{9}$ tombstoning) to more general responsibility for health requires an argument from analogy, a more complex and controversial technique (Macagno and Walton 2009), common in bioethics and applied ethics.

The concept of responsibility for health forms a significant part of public health ethics. Discourse is frequently concerned with the notion of personal responsibility for health, and while philosophical analysis can bring clarity to the confused concept, much of the debate is political in nature. Despite its many ambiguities the concept personal responsibility for health forms part of the NHS constitution ${ }^{10}$, and is accepted by a large number of people (King's Fund 2004). There are three parts to responsibility for health (Snelling 2012): (1) a moral agent having (2) responsibilities and (3) liable to be held responsible in failing to meet them. This paper discusses the second part, responsibilities, and in doing so makes some assumptions about the nature of moral agency (the first part), and virtually ignores the third part (being held responsible).

Dworkin (1988) suggests that there is an essential contradiction between autonomy and obligation, and this is certainly the case where autonomy can mean simply the supremacy of personal choice and taking responsibility for health can mean doing what you are advised to do. However, the concepts of autonomy and obligation are not necessarily in conflict; the problem is that in this model obligations are defined by others. Obligations understood within

\footnotetext{
${ }^{9}$ To be clear, this is a moral maxim; forbidding means that tombstoning is wrong. It does not follow that it should be prevented or that sanctions should follow its performance.

${ }^{10}$ Under the heading 'Patients and the public - your responsibilities' the wording was initially: 'You should recognise that you can make a significant contribution to your own, and your family's, good health and wellbeing, and take some personal responsibility for it.' In the public consultation just concluded, the word 'some' is removed so that it reads '.... and take responsibility for it.' The explanation is that this is a 'technical amendment - minor drafting change,' (Department of Health 2012), though a more significant reading could be made.
} 
an individual moral assessment augment rather than contradict personal autonomy, forming the process of moral decision making rather that the outcome, externally derived. The obligations are, principally, private obligations, and as the objections of the imagined tombstoner show, these are formulated in terms of acts rather than rules. In the private domain our responsibility is to use act utilitarianism effectively, and this amounts to two duties: the epistemic duty and the reflective duty. These interrelated obligations form our responsibilities for health.

\section{Epistemic duty.}

The epistemic duty is a duty to seek knowledge, to gather evidence, and at least on certain topics, a duty which stands in need of very little justification (Levy 2006). The epistemic duty requires moral agents to enquire about the likely effects that their behaviour has on their health and its purpose is to enable and facilitate the reflective duty.

\section{Reflective Duty (1) Harms}

The reflective duty requires an individual to place his health threatening action(s) in the context not only of his own life but also the lives of others affected by them. This includes family and friends but also the wider community if the behaviour has a financial or opportunity cost where there is socialised medicine. Several levels of reflection require consideration under this duty. The highest level requires deep reflection about the meaning of the good life and while the reflective duty encourages this it certainly does not require it. It does require, however, some consideration of the effect that health threatening behaviour has on others. The harms that should be considered fall broadly into three categories.

1. Direct harms resulting from the activity itself including injuring someone by jumping on him while tombstoning, or exposing others to second hand tobacco smoke.

2. Indirect harms caused not by the activity but by resultant ill health. These can be suffered (2a) by those immediately affected by poor health or death, like family members who are disadvantaged financially or who are harmed emotionally, and are also suffered (2b) by society generally through a number of mechanisms including in some cases opportunity costs in lieu of treatment. ${ }^{11}$

\footnotetext{
${ }^{11}$ This might be more difficult to apply than might be thought. In a systematic review of the literature between 1997 and 2007, Allender et al.. (2009) could find only two studies which calculate the financial cost of smoking related UK healthcare costs. Updating the figures, they suggest that these costs amount to $£ 5.17$ billion in 2005 -6 , compared with a figure, from the 2009 budget, of $£ 8.1$ billion raised in tobacco taxation, and a total NHS budget of $£ 86.4$ billion (H M Treasury 2009). Similarly, alcohol taxation raises $£ 9$ billion from alcohol receipts
} 


\section{Reflective Duty (2) Benefits}

It should be noted first of all that there is claimed to be wide benefit in facilitating autonomous choice, and this is a reason why respect for autonomy has become so dominant in society generally and particularly so in bioethics. Gillon (2003) among others makes this point in defence of respect for autonomy being regarded as 'first among equals' in the principlist scheme. He explains that enjoyment of eating fatty food results in an autonomous decision to carry on eating despite knowing and agreeing that giving them up would 'be better for me' (p.310). He seems to mean here better for his health rather than better for him generally but it appears to be on the latter grounds that he determines to continue his indulgence of these 'delectable' foods. The reflective duty encourages clarity over the issues of benefit to avoid the error of conflating what's good for health and what's good more generally. Because these more general benefits cannot usually be described as 'health benefits' they are seldom taken into account by health maximising health promoters. When he was Secretary of State for Health, Dr John Reid caused a furore when he was reported as saying 'As my mother would put it, people from those lower socio-economic categories have very few pleasures in life and one of them they regard as smoking' (BBC 2004). It is of interest that he is reported as saying that the rationale for his reluctance to disapprove is that individuals should not be patronised, but nevertheless it is a rare acknowledgement that people derive pleasure from smoking and drinking and eating, and in some cases this pleasure is more deep rooted, forming a part of character, desired or otherwise. See for example Oliver Reed's quotation that 'I don't have a drink problem. But if that was the case and doctors told me I had to stop I'd like to think I would be brave enough to drink myself into the grave, ${ }^{12}$ (Sellars 2008).

What might be considered an extreme case of the tensions between risk and pleasure is provided by the adventures of Andrew McAuley, who left his wife and small child on the Australian shoreline in December 2006 and paddled into the sea fulfilling a long held ambition to kayak unaided to New Zealand. Two months later he drowned, agonisingly close to reaching his goal. His widow, Vicki McAuley wrote a book detailing their life together as

(Collis et al 2010) and alcohol harm costs the NHS approximately £3.5billion annually (National Treatment Agency for Substance Misuse, 2013)

${ }^{12}$ His bravery deserted him in 1987 when he gave up drinking for a year because of kidney problems, but nevertheless he died at 61 from a heart attack, an acute episode of a disease known to be associated with high levels of alcohol consumption. There is a line between autonomous choice and autonomy-restricting addiction, and Oliver Reed probably stepped over it. This very important point is not considered here. 
well as the planning and execution of the expedition. After paddling out of the bay, Andrew McAuley talks to a bow mounted camera:

I'm really worried I'm not going to see my wife again, and my little boy. And I'm very scared...I'm very scared. I've got a boy who needs his father... and a wife who needs a husband, and I'm wondering what I'm doing here. I'm wondering why I'm doing this, I really am. And I don't have an answer.

People ask me why, and I love adventure.

(McAuley 2010 p.6)

These examples of lives defined by adventure or hedonism do not extend to the millions of people smoking and drinking and eating more than recommended, but they do illustrate that these habits and many others which threaten health can contribute to a good life variously defined because they are enjoyable and self-chosen; something that health promotion aimed solely at changing behaviour fails to recognise. Kekes (2008 p.10) states the case eloquently:

Moralists forget that morality involves not merely a set of commands and prohibitions, but also the pursuit of an enjoyable life. No reasonable person can deny that we all have responsibilities, but it is just as important to recognise that enjoyment must be part of any life that could reasonably be called good.

\section{Reflective Duty (3) Calculations}

Act or Rule?

A problem for the comparison of tombstoning with the more general targets of health promotion is that health promotion is formulated as rules, whereas the tombstoner more readily uses acts in his preferred utilitarian calculations. Although there are clear differences in how to calculate right action between acts and rules, Brad Hooker (2000b), who has advanced a detailed account of rule utilitarianism, concedes that in ordinary morality, not only are the outcomes often the same between act and rule utilitarianism, but also the versions agree on how, generally speaking, people should go about their day to day moral thinking. As Upton (2011) points out, we do best by careful deliberation on acts which require it, but that generally the familiar rules 'with which we have grown up' (p.435) serve as an effective starting point. Such deliberation results in the distance between act and rule utilitarianism being less significant in practice than might be expected, confirming that a kind of amalgam version is useful and workable as an action guide despite the apparently fatal objections to both theories operated alone.

It is difficult to be clear about what constitutes an act for the more common targets of health promotion. For smoking, and moving from the general to the specific, the act could be (at a 
pinch) being a smoker, or (just) smoking, or smoking a cigarette, or even taking a drag from a cigarette. It would be absurd to require a utility calculation before each drag or each cigarette, and in any case they would be identical and could lead to fallacious reasoning similar to the fallacy of the heap of sand or the fallacy of the beard (Clark 2002): this drag on this cigarette won't cause me any long term harm, therefore neither will the next, nor the next...therefore smoking won't cause me any long term harm. Advocating act utilitarianism for smoking so that it is analogous to tombstoning requires the act to be conceptualised more generally, as the act of being a smoker; that is the thing (like a single act of tombstoning) that is harmful to health. This will apply to established smokers but a different calculus would apply to those who have never smoked or those who have smoked and given up but are vulnerable to restarting. In these cases the act of lighting or smoking a cigarette may lead to the individual (re)turning from a being non-smoker into a smoker (that is the thing that is harmful) and so the smoking of a single cigarette or perhaps a few cigarettes over the course of an evening assumes a greater significance here than for the established smoker. Arriving at a theoretical preference for the level of analysis is ambiguous between and within the practical cases of tombstoning and smoking, but accepting, with Hooker (2000b) that in practice the approaches are similar, leaves the basic tension unresolved. What is needed is a theory that can account for both levels of evaluation.

\section{R.M Hare's Dual level account}

Hayry's view (in 1994) was that R.M.Hare's dual level account in his book Moral Thinking, offered the best solution to the debate between act and rule versions of utilitarianism. Generally we can be guided by the intuitive rules which constitute the first level of moral thinking, formed by experiences and moral emotions, but conforming to a version of general rule-utilitarianism. The second level, acts, requires critical thinking that has selected the set of prima facie principles for use in intuitive thinking, and also can be employed when the intuitive principles conflict. There is potentially some confusion as to the extent to which the prima facie rules need to be universaliseable. If they are universal rules then the formulation will be of the sort that 'people shouldn't smoke', whereas an individual is more likely to formulate a rule in terms of whether 'he should smoke" ${ }^{, 13}$, or perhaps even (recognizing that this is problematic for utilitarianism) that 'he is permitted to smoke.' Hare's critical level equates act utilitarian calculations with that kind of rule utilitarianism 'which allows its rules

\footnotetext{
${ }^{13}$ Universalised, this might take the form of everyone in circumstances that are the same as mine should smoke (or is permitted to smoke).
} 
to be of unlimited specificity and which therefore is not distinguishable from actutilitarianism' (1981 p.43). For practical purposes it does not really matter at the critical level whether the agent specifies universal rules so that they apply to his circumstances, or takes an outright act-utilitarian approach, but both of these approaches stand in opposition to the rules generated by orthodox health promotion which are much more general in orientation.

\section{What to maximise and how.}

Having reflected on the wider risks and the benefits of the act or the behaviour under consideration, utilitarian moral theories require that a calculation be undertaken, placing the positive value of the act or behaviour against the potential harm that injury or death brings to those affected. The maximised value can be variously chosen; health, welfare, utility, preference or happiness, and while difficulty in calculation is acknowledged as a significant problem with all utiltarian theories, weighing up pros and cons of decisions, and not only in the moral domain, is a fundamental part of everyday life. It is clear what is meant when we say that all things considered this or that decision is better even though we would be hard pressed to show our detailed working out.

A problem with this is that if the decision making process cannot be articulated neither can it be scrutinised. In law, decision making processes can be challenged via judicial review which can find that decision making processes considered irrelevant criteria or failed to consider criteria which they ought to have done, but no appeal process exists in the reflective duty. It would be difficult to separate an objection, from a person whose objections matter, that the wrong conclusion (that I go tombstoning) has been reached, from an objection that the reflective process is inadequate (that the interests of my family have not been given sufficient weight). This might be a matter for discussion and potentially, blame, but ultimately it is a matter for the individual, similar to the question of what property should be maximised. Only a person at the centre of the decision knows his own thoughts and feelings and is much more able than a disinterested observer to judge the likely ${ }^{14}$ consequences of his action on those who are affected by it. An attempt to prescribe a decision making process is vulnerable to the same moralising critiques as prescribing actions, though the defence of moral expertise is

\footnotetext{
${ }^{14}$ Likely rather than actual consequences. A critique of all forms of utilitarianism is that consequences are very difficult to predict. Empirical research can diminish the strength of the critique. See Lang (2008) on the cluelessness objection.
} 
probably stronger here. The reflective duty requires a process of calculation and recognises that there are many ways to perform it. The choice and justification of maximising property and decision making procedures are matters for the actor, and he is accountable for them. At the centre of her grief at losing her husband and father to her child, Vicki McAuley was quoted a week after his death as saying:

These are a few words that I'd like to say to my most wonderful man. To have the courage to pursue your dreams and believe that anything is possible is a rare gift ... You are our hero. You live for adventure. You've just had one incredible adventure this time, and we were with you all the way ... Ant, you have taught me how to live.

It would be easy to characterise his behaviour as selfish or reckless, and many would. But Vicki McAuley has not because she alone really knows what it meant to him, and what it would have meant for him to forgo his ambition. His epistemic and reflective duties were performed, and though the result was catastrophic, the decision was, as far as process is concerned, moral. Strawson's (1962) reactive attitudes account of responsibility defines the moral status of an act in terms of its provoked response, amply demonstrated in the anger of Sonny's parents and Vicki McAuley's pride; Andrew McAuley met his responsibilities and Sonny Wells did not.

\section{Policy Implications.}

Autonomy is (purportedly) valorised within western health care systems, and autonomous decisions need information, recognised by the need for sufficient information for valid consent for care and treatment. However, illustrated by the ready adoption of behavioural insight (Cabinet Office 2011, Yeung 2012), current practice within health promotion is not to facilitate the epistemic duty, but rather to present information in a way designed to persuade people to change their behaviour. Unlike the process of gaining consent for treatment, the value of behaviour change, predicated upon the value of health, overrides the value of facilitating autonomous decisions. As Allmark and Tod (2007) have pointed out, health education, unlike other forms of education is evaluated not in terms of what people know but whether behaviour has changed.

For example, the strategy to reduce drinking is skewed away from education and towards behaviour change. Putting to one side the fact the evidence upon which the recommendations are based will be almost 20 years old by the time a review is completed (House of Commons 
Science and Technology Committee 2011) current guidance, though written for a public audience, is difficult to interpret. A key document is 'Your drinking and You' (NHS 2012), which gives the lower risk guidelines as 'No more than 3-4 units on a regular basis'. Clarification is offered for the word 'regular': 'Regular in this context means drinking in this way every day or most days of the week.' It is unnecessarily unclear why the daily allowance is given as 3-4 units with no indication as to whether it is 3 or 4 units. Of the 22 other countries used as comparisons in the House Of Commons Report, only Japan, the USA and Portugal (unofficially) use a range rather than a single daily amount. The definition of regular could mean four, five, six or seven days a week. None of the other countries has this ambiguity, and only Poland uses anything other than a daily or a weekly allowance. The guidance (p.2) goes on to state that if you are drinking just above the guidelines,

- Men are twice as likely to get cancer of the mouth, pharynx or larynx (part of the neck and throat), while women are 1.7 times as likely.

- Women increase their risk of breast cancer by around $20 \%$.

- Men and women are both 1.7 times as likely to develop liver cirrhosis.

- Men are 1.5 times as likely to develop high blood pressure, with women 1.3 times as likely

For even higher consumption the same categories, adjusted for increased likelihood are given. It is impossible for anyone to make any sort of risk assessment based on this information because the likelihoods of developing the diseases highlighted are given in relative rather than absolute terms ${ }^{15}$. The figures are virtually meaningless, and in addition the consequences of developing the diseases are not given - my blood pressure may be higher, but what does this mean for my health? Calculation of risk requires both understanding of the likelihood and the consequences of an adverse event occurring.

Information in smoking cessation material is similarly skewed. While there is evidence that mass media campaigns have some success in smoking cessation (Farelly et al. 2012, Bala et al. 2008), the evidence about how the messages are presented is inconclusive. It has been recommended that preference should be given to negative messages (Durkin et al. 2012) and there is some evidence to suggest that emotionally evocative advertisements work better than descriptive ones (Durkin et al. 2009). Farelly et al.'s (2102) study lumped together emotional and/or graphic antismoking advertising and found this category more effective in

${ }^{15}$ A point given wider discussion in Fitzpatrick's (2001) celebrated polemic 
quitting behaviour than comparison advertisements. The most recent $\mathrm{UK}$ advertisement ${ }^{16}$ graphically shows a tumour growing on the side of a cigarette as it is being smoked, and while this obviously reinforces the proven links between smoking and cancer at the group level, like the alcohol information discussed earlier, it does nothing to facilitate epistemic duty and therefore reflective duty, because risk cannot be calculated ${ }^{17}$. Other recent advertisements have invited smokers to consider the effect their habit has on others, for example from 2009, the 'scared and worried"18 campaign showed a boy explaining to camera what he was not worried about, but concluded with a shot of him with his father smoking a cigarette on a fishing trip: ‘ ...but I am worried about my Dad smoking. I'm worried that my dad will die.' In an emotionally challenging way, this advertisement invites the reflective duty, more consistent with the responsibilities for health outlined in this paper, highlighting that the wrongness of the father's smoking is in the pain expressed in the boy's visible concern. In a similar vein, an advertisement from Australia ${ }^{19}$ shows a young boy of about 4 , standing alone in a train station having been separated from his mother. His concern turns to distress and as his tears begin the narrator says: 'if this is how your child feels after losing you for a minute, just imagine if they lost you for life.'

Although of interest, the reworking of mass media campaigns alone will not satisfy facilitation of responsibility for health as conceptualised by the epistemic and reflective duties. It would require a wholesale shift from 'getting' people to change their negatively evaluated behaviour to giving them information to enable an autonomous decision and encouraging them to consider the interests of others as they make it. The most that can be hoped for is that the Government and its agencies embark on a fuller justification of its strategies. This may mean a renewed commitment with explanation of the operationalization of the concept of autonomous decision making, and ways of encouraging a more morally reflective life, though this is clearly a much bigger issue than health promotion.

This is not to say that regulation and restrictions on unhealthy food availability, or tax regimes that increase the price of alcohol and cigarettes are necessarily unethical. Though something being a fitting matter for private moral assessment is insufficient for it being a

\footnotetext{
${ }^{16}$ Available at http://www.bbc.co.uk/news/health-20805059 (last accessed 3rd January 2014)

${ }^{17}$ For a discussion on how these messages can foster autonomy see Barton (2013)

${ }^{18}$ Available at http://www.theguardian.com/society/video/2009/feb/18/worried-smoking-children (last accessed 3rd January 2014)

${ }^{19}$ Available at http://www.youtube.com/watch?v=SfAxUpeVhCg (last accessed 3rd January 2014)
} 
proper subject for public morality, this does not mean that the public has no interest in behaviour affecting individual health. But at the very least the essentially private nature of these behaviours requires public health authorities to provide a full explanation for policy interventions seeking regulation. Something within the sphere of our individual influence being bad not for us, but our health, narrowly defined is not sufficient. Our behaviour causing direct harm to others probably is enough, though causing indirect harm probably is not. Financial reasons alone present further difficulties in calculation in a system of socialised medicine and these provide better reasons for some measures (tax) than for others (bans).

\section{Conclusion (1) - What's wrong with tombstoning?}

The account that I have offered is more aligned to the approach to tombstoning advocated by RoSPA and RNLI, and the analysis of this paper shows that it is because it focuses upon and facilitates the epistemic duty. Whether individual cases of tombstoning can be regarded as morally permissible depends on whether the framework of facilitation offered has been followed, and whether there has been adequate reflective attention given to the facts. If they have, tombstoning is morally defensible. I say defensible rather than permissible because the reflection is subject to evaluation and therefore disagreement and so should be regarded as a necessary rather than sufficient condition. A search for 'people are awesome, ${ }^{20}$ via the video sharing website YouTube further illustrates this. With very few exceptions, the people undertaking all manner of daredevil feats, tombstoning, base jumping, tightrope walking and extreme cycling are properly prepared and equipped, and it is assumed that what might be called this 'professional' approach implies that they have given the activity serious consideration. It is easy to accept the invitation to marvel at the skill, courage, enjoyment and sheer verve of the acrobats. People really are awesome. Contrast this with a search for 'ultimate fails, ${ }^{21}$. Amongst the assorted pratfalls, confused pets and distracted walking into glass doors are many examples of people falling off bikes and skateboards and hurting themselves. Like Sonny Wells, most 'victims' are ill prepared. There are few helmets or protective pads, and failure often is the result of laughingly inadequate preparation though

\footnotetext{
${ }^{20}$ For example http://www.youtube.com/watch?v=hhKXsLFKYqc (last accessed 3rd January 2014)

${ }^{21}$ For example http://www.youtube.com/watch?v=Ujwod-vqyqA (last accessed 3rd January 2014)
} 
onlookers' initial mirth often fades with the realisation that serious injury may have resulted. What is wrong with tombstoning? Nothing at all, potentially.

\section{Conclusion (2) Responsibility for health.}

A change in emphasis from responsibility for health as following public health advice to a model of responsibility which instead requires private process is closer to the espoused predominant value of respecting autonomy. It will require the giving of information about health in a more neutral way to facilitate the epistemic duty. The major challenge is in the reflective duty, which becomes the principal personal responsibility for health. It will remain the case that decision making will be influenced by factors outside individual control, but these will be reduced by a more reflective approach to deciding what our individual good life consists in and how this impacts on those who share our lives. Our responsibilities, that is our obligations, will be more clearly identified but not by the state in various guises. It probably is the case that most of us do have moral obligations in respect of our health, and that they are largely unfulfilled. Insufficiently challenged weakness of will in the consumption of tobacco and alcohol and all manner of health threatening habits possibly are, for many of us, immoral. And though the end results are similar, the key difference between this conclusion and the similar, if unstated, one of orthodox health promotion, is that this account of responsibility for health is one of individual process rather than collective outcome. The only duties we all have in respect of our health are the epistemic and reflective duties, though other autonomycompatible responsibilities will follow for many. 


\section{References}

Aiken, M. (2009). Exclusive: MSP calls for ban on online videos showing tombstoning. Daily Record August $16^{\text {th }} 2009$.

Allender, S., Balakrishnan, R., Scarborough, P., Webster, P., Raynor, M. (2009). The burden of smoking related ill health in the UK. Tobacco Control, 18; $262-267$.

Allmark P. and Tod A. (2007). Philosophy and health education: the case of lung cancer and smoking. In Drummond J.S. and Standish P. (eds) (2007) The Philosophy of Nurse Education. Chapter 2, pp 46-58. Palgrave Macmillan: Basingstoke.

Archard, D (2011) Why Moral philosophers are not and should not be moral experts. Bioethics, 25(3):119 - 127.

Bala, M., Strzeszynski, L., \& Cahill, K. (2008). Mass media interventions for smoking cessation in adults. Cochrane Database Systematic Review, 1.

Barton, S. (2013). How tobacco health warnings can foster autonomy. Public Health Ethics, 6(2):207-219

Brassington, I. (2013). What's the Point of Philosophical Bioethics? Health Care Analysis, 21 (1):20-30.

British Broadcasting Corporation (2004). Smoking 'working-class pleasure' http://news.bbc.co.uk/1/hi/uk_politics/3789591.stm (last accessed 3rd January 2014).

British Broadcasting Corporation (2007). Youth charged over tombstoning. [on line] http://news.bbc.co.uk/1/hi/scotland/tayside_and_central/8077061.stm (last accessed 3rd January 2014).

British Broadcasting Corporation (2008a) Photo shows injured 'tombstoner' http://news.bbc.co.uk/1/hi/england/hampshire/7403359.stm (last accessed 3rd January 2014).

British Broadcasting Corporation (2008b). Police to use tombstoning video http://news.bbc.co.uk/1/hi/england/hampshire/7465497.stm (last accessed 3rd January 2014).

British Broadcasting Corporation (2008c). Remorse of paralysed tombstone [on line] http://news.bbc.co.uk/1/hi/england/hampshire/7459821.stm (last accessed 3rd January 2014).

British Broadcasting Corporation (2011a). Groups of tombstoners in Devon targeted by police order. [on line] http://www.bbc.co.uk/news/uk-england-devon-12878996 (last accessed 3rd January 2014).

British Broadcasting Corporation (2011b). Tombstoning victim Sonny Wells in Dover safety DVD) http://www.bbc.co.uk/news/uk-england-12473930 (last accessed 3rd January 2014) 
Cabinet Office (2011). Behavioural Insights Team Annual Update 2010-11 London: Cabinet Office Behavioural Insights Team.

Chandler, J. (2007). Andrew McAuley was not crazy or reckless but crossing the Tasman Sea in a kayak was a calculated, planned gamble he lost. The Age $17^{\text {th }}$ February 2007 http://www.theage.com.au/news/national/andrew-mcauley-was-not-crazy-or-recklessbut-crossing-the-tasmansea-in-a-kayak-was-a-calculated-planned-gamble-helost/2007/02/16/1171405447066.html (last accessed 3rd January 2014).

Clark, M. (2002). Paradoxes from A to Z. London: Routledge.

Coggon, J. (2012). What Makes health Public? Cambridge: Cambridge University Press.

Collis, J., Grayson, A, and Johal, S. (2010) Econometric Analysis of Alcohol Consumption in the UK. HMRC working paper 10. London; HMRC.

Department of Health (2010). Our Health and Wellbeing Today. London: Department of Health [on line] https://www.gov.uk/government/uploads/system/uploads/attachment_data/file/215911 /dh_122238.pdf (last accessed 4th January 2014)

Department of Health (2012) A consultation on strengthening the NHS Constitution. London: Department of Health. [on line] http://consultations.dh.gov.uk/nhsconstitution-team/nhs-constitution (last accessed 3rd January 2014).

Dover District Community Safety Partnership (2011). The dangers of tombstoning (video) available at http://www.youtube.com/watch? v=hEJUjAeJE48 (last accessed 3rd January 2014).

Durkin, S. J., Biener, L., \& Wakefield, M. A. (2009). Effects of different types of antismoking ads on reducing disparities in smoking cessation among socioeconomic subgroups. American Journal of Public Health, 99(12): 2217 - 2223.

Durkin, S., Brennan, E., \& Wakefield, M. (2012). Mass media campaigns to promote smoking cessation among adults: an integrative review. Tobacco Control, 21(2):127138.

Dworkin, G. (1988). The Theory and Practice of Autonomy. Cambridge: Cambridge University Press.

Farelly C., Duke, J.C., Davis,K.C. Nonnemaker, J.M., Kamyab, ., Willett, J.G et al. (2012). Promotion of Smoking Cessation with Emotional and/or Graphic Antismoking Advertising. American Journal of Preventative Medicine, 43(5):475-482.

Fitzpatrick, M. (2001). The Tyranny of Health: doctors and the regulation of lifestyle. London: Routledge.

Foot, P. (1985). Utilitarianism and the Virtues. Mind, 94(374):196-209. 
Gert, B. (2005). Morality' Its Nature and Justification. Revised Edition. Oxford: Oxford University Press.

Gillon, R. (2003). Ethics needs principles - four can encompass the rest—and respect for autonomy should be "first among equals". Journal of Medical Ethics, 29(5):307-312.

Goodin, R.E. (1995). Utilitarianism as a Public Policy. Cambridge: Cambridge University Press.

Gordon, J-S. (2012). Moral philosophers are moral experts! A reply to David Archard. Bioethics. Advance access published $19^{\text {th }}$ September 2012 DOI 10.1111/j.14678519.2012.02004.x

Greene, J (2013) Moral Tribes: Emotion, Reason, and the Gap Between Us and Them. New York: The Penguin Press.

Hare, R.M. (1981). Moral Thinking. Its Levels, method and point. Oxford: Oxford University Press.

Hayry, M (1994). Liberal Utilitarianism and Applied Ethics. London Routledge.

H.M. Treasury (2009). Budget 2009. London; The Stationery office.

Hooker, B. (2000a). Sidgwick and common-sense morality. Utilitas, 12(3):347-360.

Hooker, B. (2000b). Ideal code, real world: A rule-consequentialist theory of morality. Oxford: Oxford University Press.

Holland, S. (2007). Public Health Ethics. Cambridge: Polity Press.

House of Commons Science and Technology Committee (2011). Alcohol Guidelines. $11^{\text {th }}$ report of session 2010 - 2011. London: The Stationary Office Limited.

Jacobson, D. (2008). Utilitarianism without Consequentialism: The Case of John Stuart Mill. Philosophical Review, 117(2):159-191.

Kekes, J. (2008). Enjoyment. Oxford: Clarenden Press.

King's Fund (2004). Public attitudes to public health policy. London; Kings Fund.

Lang, G. (2008). Consequentialism, Cluelessness, and Indifference. The Journal of Value Inquiry, 42(4):477-485.

Levy, N. (2006). Open-mindedness and the duty to gather evidence. Public Affairs Quarterley, 20(1):55- 66.

Macagno, F., and Walton, D. (2009). Argument from analogy in law, the classical tradition, and recent theories. Philosophy and rhetoric, 42(2):154-182

McAuley, V. (2010). Solo. Sydney: Macmillan. 
McKinnon, C. (2006). Toleration: A Critical Introduction. London: Routledge.

National Health Service (2012). Your drinking and you. The facts on alcohol and how to cut down. London: Department of Health [on line]

http://www.nhs.uk/Change4Life/supporterresources/downloads/408723_Your_Drinking_And_You.pdf (last accessed 3rd January 2014).

National Treatment Agency for Substance Misuse (2013) Alcohol treatment in England 2011-2012. [on line] http://www.nta.nhs.uk/uploads/alcoholcommentary2013final.pdf (last accessed 3rd January 2014).

Rothstein, M. (2004). Are Traditional Public Health Strategies Consistent with Contemporary American Values? Temple Law Review, 77(2), 175.

Royal National Lifeboat Institution (undated) Tombstoning [on line] http://rnli.org/safetyandeducation/stayingsafe/beach-safety/Pages/Beach-safetyadvice-content/Hazards-and-dangers-content/Tombstoning.aspx (last accessed 3rd January 2014).

Royal Society for the Prevention of Accidents (RoSPA)(undated). Tombstoning - 'Don't jump into the unknown' [on line] http://www.rospa.com/leisuresafety/adviceandinformation/watersafety/tombstoning.as px (last accessed 3rd January 2014).

Seedhouse, D. (2009). Ethics the heart of healthcare ( $3^{\text {rd }}$ edition). Chichester: John Wiley and sons.

Sellers, R. (2008). Hellraisers; The life and inebriated times of Richard burton, Richard Harris, Peter O'Toole and Oliver Reed. London: Preface.

Sinnott-Armstrong, (2012) "Consequentialism", The Stanford Encyclopedia of Philosophy (Winter 2012 Edition), http://plato.stanford.edu/archives/win2012/entries/consequentialism/ (Last accessed 3rd January 2014).

Snelling, P.C. (2012). Saying something interesting about responsibility for health. Nursing Philosophy, 13(3):161-178.

Spranzi, M. (2012). The Normative Relevance of Cases. Cambridge Quarterly of Healthcare Ethics, 21(4):481-492.

Sterba, J.P. (2005). The Triumph of practice over Theory in Ethics. New York: Oxford University Press.

Strawson, P. (1962). Freedom and Resentment. Proceedings of the British Academy, 48, 1 25. Reprinted in Watson, G. (ed) (2003). Free Will (second edition) Oxford: Oxford University Press, pp $72-93$.

Streumer, B. (2003). Can Consequentialism Cover Everything? Utilitas, 15(2):237-247. 
Upton, D., and Thirlaway, K. (2010). Promoting Healthy Behaviour. Harlow: Pearson Education Limited

Upton, H. (2011). Moral Theory and Theorizing in Health Care Ethics. Ethical theory and moral practice, 14(4):431-443.

Walker, D. (2007). Tombstoning - a giant leap into the unknown. Staying Alive, November 2007. [on line] http://www.rospa.com/leisuresafety/Info/PublicationsJournals/stayingalive-tombstoning.pdf (last accessed 3rd January 2014).

Williams, B (1985) Ethics and the Limits of Philosophy. London: Fontana Press.

Yeung, K. (2012). Nudge as Fudge. The Modern Law Review 75(1)122-148. 